\title{
TÉCNICA SIMPLES PARA IDENTIFICAÇÃO DE FÊMEAS DE TILÁPIA NILÓTICA (Oreochromis niloticus) REALIZANDO INCUBAÇÃO ORAL DOS OVOS ${ }^{1}$
}

\author{
A SIMPLE TECHNIQUE TO IDENTIFY NILE TILAPIA FEMALES \\ (Oreochromis niloticus) INCUBATING EGGS ORALLY
}

Marco Aurélio Rotta ${ }^{2}$ Luís Orlando Bertolla Afonso ${ }^{3}$

- NOTA -

RESUMO

Em laboratórios de aquacultura que trabalham com reprodução de tilápia nilótica (Oreochromis niloticus) utilizando água cristalina, é freqüentemente necessário verificar se as fêmeas estão realizando incubação oral dos ovos. Quando não se tem prática a olho nu, essa constatação torna-se difícil e demorada. Nos casos em que não se consegue identificar visualmente a incubação, é necessário o uso de técnicas que estressam as fêmeas e que, freqüentemente, danificam os ovos. O presente trabalho descreve uma técnica simples para a identificação de fêmeas de tilápia nilótica que estão realizando incubação oral, em água cristalina, através do uso de espelho. Os resultados demonstram que é possível identificar as fêmeas realizando incubação oral com $100 \%$ de eficiência.

Palavras-chave: desova, estresse, sexagem, espelho, água cristalina.

\section{SUMMARY}

In aquaculture laboratories which work with Nile tilapia (Oreochromis niloticus) reproduction and use crystalline water, is frequently necessary to verify whether the females are incubating orally the eggs. The identification of the females when there is not know-how is difficult and slow, and in most cases is stressful and damage the eggs. This study describes a simple technique, using a mirror, to identify Nile tilapia incubating eggs orally in crystalline water. The results showed that is possible to identify the females which are incubating orally with $100 \%$ efficiency.
Key words: spawning, stress, sexual identification, mirror, crystalline water.

A tilápia nilótica (Oreochromis niloticus) é uma espécie de peixe cujas fêmeas realizam incubação oral (ROTHBARD \& PRUGININ, 1975; RANA, 1986; MACINTOSH \& LITTLE, 1995). AFONSO et al. (1993) citam que, embora seja prática comum nos laboratórios remover os ovos da boca da fêmea dois a três dias após a desova, a incubação pode iniciar em períodos anteriores, o que não ocasionaria problemas no processo de incubação. Esse manejo também promove a sincronização e o aumento da freqüência das desovas (RANA, 1986; MACINTOSH \& LITTLE, 1995; TACON et al., 1996; BHUJEL, 2000). Segundo BHUJEL (2000), parece haver uma relação inversa entre o intervalo das coletas dos ovos e a sua produção. Muitas vezes os laboratórios de reprodução, que trabalham com essa espécie, deparam-se com o problema de identificação das fêmeas que estão na fase inicial de incubação oral. As fêmeas, quanto em incubação, não se alimentam, tendem a se isolar e abrem muito pouco a boca para realizarem os movimentos respiratórios. (MACINTOSH \& LITTLE, 1995). As

\footnotetext{
${ }^{1}$ Financiamento FAPERGS e CNPq.
}

${ }^{2}$ Engenheiro Agrônomo, Aluno de Mestrado do Programa de Pós-graduação em Zootecnia, Departamento de Zootecnia (DZ), Universidade Federal do Rio Grande do Sul (UFRGS).

${ }^{3}$ Zootecnista, Professor Adjunto I ,PhD., DZ, UFRGS, Av. Bento Gonçalves 7712, 91540-000, Porto Alegre, RS. E-mail: bafonso@pro.via-rs.com.br. Autor para correspondência. 
características mais marcantes de uma fêmea incubando é o desenvolvimento de um "papo" e a dilatação da região opercular (RANA, 1986). A identificação desses animais em tanques com água cristalina é difícil e pouco precisa quando realizada por indivíduos sem prática. Como rotina, normalmente se capturam todos os animais e, com as fêmeas que estão incubando, faz-se a lavagem bucal. Esse manejo é estressante e pode ocasionar a perda ou danificação dos ovos ou larvas. A avaliação dos métodos de incubação e do desenvolvimento embrionário de peixes necessita formas práticas, precisas e seguras para a obtenção de ovos (RANA, 1986). Dessa forma, o objetivo deste trabalho foi descrever uma técnica simples para a identificação de fêmeas de tilápia nilótica, realizando incubação oral, com o uso de um espelho. Para a confecção do equipamento, foi utilizado um espelho retangular com dimensões de 20 x $30 \mathrm{~cm}$, uma lâmina de acrílico em forma de seta, com dimensões de $24 \mathrm{x}$ $45 \mathrm{~cm}$, e um cabo de madeira. O espelho foi amarrado com arame nas quatro extremidades da placa de acrílico, a qual foi presa com parafusos ao cabo de madeira (Figura 1). Duas famílias de tilápia nilótica, constituídas por quatro fêmeas e um macho cada uma, foram colocadas em caixas de cimentoamianto com $1.000 \ell$ de volume total e $630 \ell$ de volume útil, equipadas com filtro biológico e aerador. A verificação consistia na colocação do equipamento dentro da água, em um ângulo entre $30^{\circ}$ e $45^{\circ}$, de modo que se pudesse enxergar se as fêmeas apresentavam papo. Para a melhor movimentação do equipamento, todos os objetos que se encontravam dentro da caixa (filtro biológico e aerador) foram retirados. No momento que se detectava, através do espelho, uma fêmea incubando, a mesma era capturada com auxílio de puçá com abertura de malha de 50 micras e transferida para um balde com capacidade de $20 \ell$. No balde, era feita a lavagem bucal para a retirada dos ovos. Da mesma forma, os animais que não estavam realizando incubação oral, conforme verificação com o equipamento, foram submetidos ao mesmo manejo para confirmação. Ocorreram 10 desovas no período

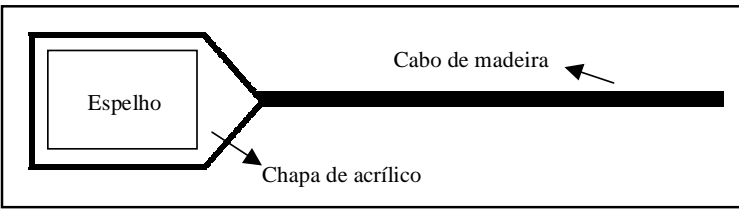

Figura 1 - Desenho esquemático do equipamento para identificação de fêmeas de tilápia nilótica realizando incubação oral. de um mês e as fêmeas foram identificadas com o equipamento com $100 \%$ de precisão. A característica mais evidente nas fêmeas que estavam incubando, visualizada com o auxílio do espelho, foi a presença do papo. Outro indicativo de incubação oral foi o fato de as fêmeas que estavam incubando não abriam muito a boca, porém, na maioria das vezes, a abertura era suficiente para visualizar, através do equipamento, a movimentação dos ovos dentro da boca. A identificação dos animais que não estavam incubando foi também $100 \%$ eficiente com o uso do espelho. Todas as vezes em que se utilizou o equipamento, este foi colocado com cuidado dentro das caixas, com o intuito de minimizar o estresse dos animais, técnica que mostrou ser bastante eficiente. A diminuição do estresse durante a verificação da incubação, e posterior captura dos peixes para lavagem bucal, ficou clara pelo fato de as fêmeas não liberarem, espontaneamente, os ovos dentro do puçá. Ficou evidente no manejo do equipamento que a utilização de dimensões superiores às descritas pode comprometer a movimentação deste dentro d'água. Logo, deve-se chegar a um tamanho que seja suficiente para a visualização e que também seja ágil dentro da água. Através do uso desse equipamento, é possível identificar, com segurança, eficiência e rapidez, fêmeas de tilápia nilótica que estão realizando incubação oral, com o mínimo de estresse.

\section{REFERÊNCIAS BIBLIOGRÁFICAS}

AFONSO, L.O.B, GUDDE, D.H., LEBOUTE, E.M., $\boldsymbol{e}$ t al. Método para a incubação artificial de ovos de tilápia nilótica (Oreochromis niloticus). Rev Soc Bras Zoot, Viçosa, v.22, n.3, p.502-505, 1993.

BHUJEL, R.C. A review of strategies for the management of Nile tilapia (Oreochromis niloticus) broodfish in seed production systems, especially hapa-based systems. Aquaculture, Amsterdam, v.181, p.37-59, 2000.

MACINTOSH, D.J., LITTLE, D.C. Nile tilapia (Orechomis niloticus). In: BROMAGE, N.R., ROBERTS, R.J. Broodstock management and egg and lerval quality. London : Blackwell Science, 1995. Cap.12, p.277-320.

RANA, K.J. Parental influences on egg quality, fry production and fry performance in Oreochromis niloticus (Linnaeus) and O. mossambicus. Stirling, 1986. 295p. Thesis (Ph.D. in Aquaculture) - Institute of Aquaculture, University of Stirling, 1986.

ROTHBARD, S., PRUGININ, Y. Induced spawning and artificial incubation of Tilapia. Aquaculture, v.2, p.315-32, 1975.

TACON, P., NDIAYE, P., CAUTY, C., et al. Relationships between the expression of maternal behaviour and ovarian development in the mouthbrooding cichlid fish Oreochromis niloticus. Aquaculture, amsterdam, v.146, p.261-275, 1996. 